\section{SOBRE TOPOFILIA, DE YI-FU TUAN}

TUAN, Yi-Fu. Topofilia: um estudo da percepção, atitudes e valores do meio ambiente. (Tradução de Lívia de Oliveira). Londrina: Eduel, 2012.

ISNB: 978-7216-627-0

\section{Mariana Ferreira Cisotto'}

O livro "Topofilia" de autoria do geógrafo sino-americano Yi-Fu Tuan, foi publicado originalmente em 1974. Teve sua tradução para o português em 1980, feita por Lívia de Oliveira e foi reeditado em 2012, pela Eduel. É com muito ânimo que recebo essa edição, a obra não só representa a possibilidade de um primeiro contato com a corrente humanista da geografia, através de um dos seus principais proponentes, mas também a oportunidade de resgatar essa clássica obra, podendo agora ser difundida com maior alcance.

"Topofilia" é um clássico, uma importante contribuição que YiFu Tuan deu para a epistemologia da geografia. É uma referência obrigatória para estudos não só da geografia humanista, mas também para muitos geógrafos que tem suas preocupações voltadas às relações com o ambiente, o livro propõe uma nova forma de entendimento do Homem e sua relação com a Natureza.

O geógrafo nos incita a questionar quais foram e quais são nossos ideais ambientais, como o percebemos, nos situamos, significamos o mundo que ocupamos, se propondo a examinar a percepção e os valores ambientais, mostrar a construção de valores concernente ao meio ambiente, as mudanças de visões de mundo e a distinção entre diferentes experiências ambientais.

1 Doutoranda em Geografia, Instituto de Geociências da Universidade Estadual de Campinas (IG/Unicamp). mariana.cisotto@ige.unicamp.br.

$\triangle$ Rua Cônego Pedro Banhomme, 1895, Jardim Margarida. Campinas, SP. 13077-003.

Geograficidade | v.3, n.2, Inverno 2013 ISSN 2238-0205
Nesse ótimo livro, o autor apresenta uma grande diversidade de considerações, sobre linhas bastante abrangentes, que cercam o tema da percepção humana, envolvendo literatura, antropologia, história, psicologia, pedagogia, religião e estética. Pretendendo abordar múltiplas culturas, Tuan apresenta uma desconcertante variedade de materiais e estudos que incorporam esses diferentes pontos de vista sobre o homem e o mundo, de povos de toda parte do planeta (orientais, ocidentais, austrais).

Enfatiza os aspectos subjetivos das relações humanas com o meio ambiente natural através do estudo da relação das pessoas com a natureza e dos seus sentimentos e ideias sobre os espaços. Trata do ambiente físico no imaginário social, a relação entre paisagem, memória e cultura; a experiência individual e visão de mundo construindo identificações que são compartilhadas num território comum.

Assim, nos múltiplos condicionantes, o autor identifica, como e por que, os Homens, variam temporal, histórica, cultural e individualmente sua percepção sobre o meio, o espaço que ocupam, onde constroem suas relações e significações e estabelecem diferentes valores. Nessa construção que faz com que o espaço se torne lugar.

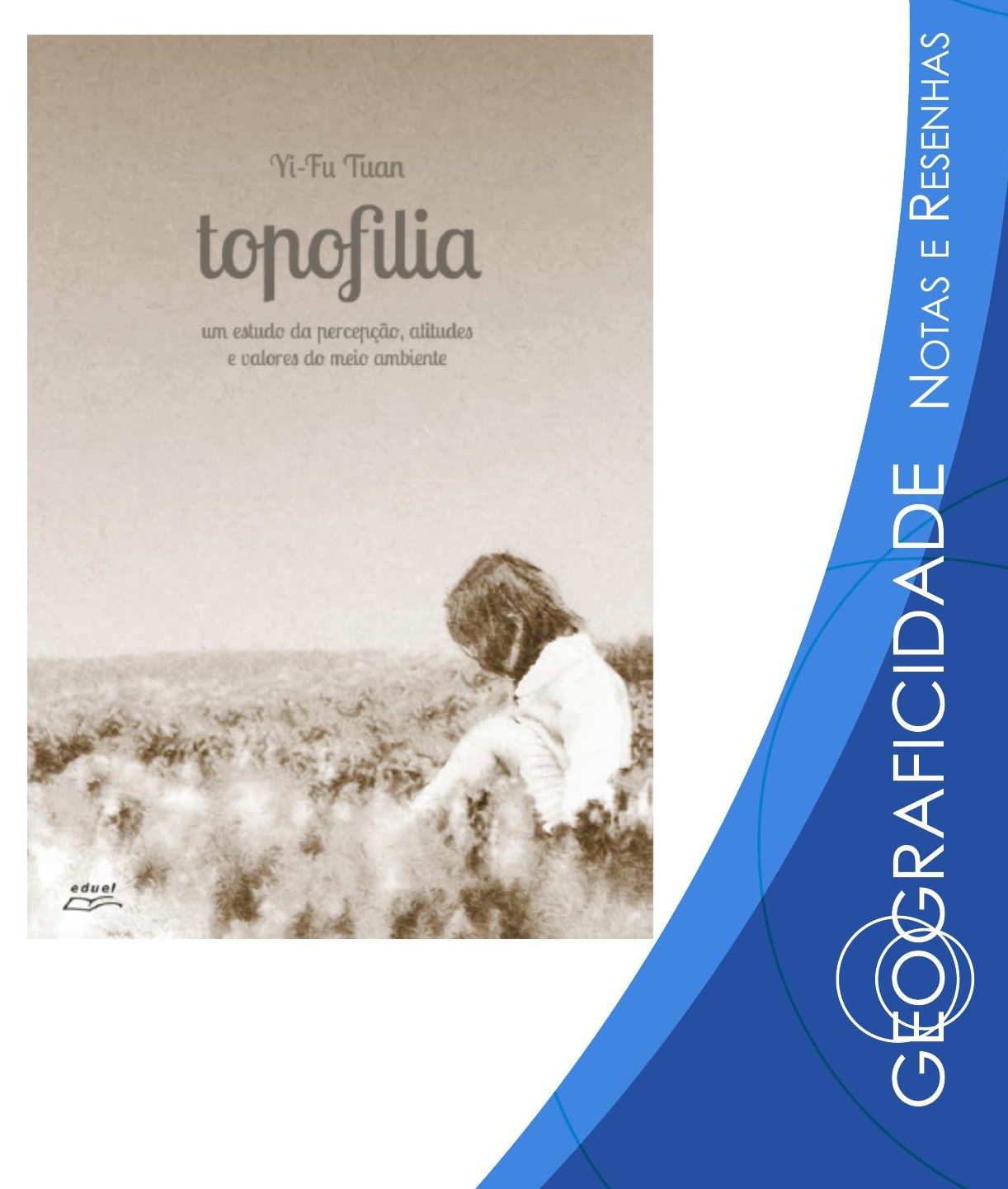


Ainda que em alguns momentos de forma bastante sucinta, dado a complexidade, por exemplo, da conformação dos mundos pessoais, o autor é muito eficiente para elucidar a carga de influência da individualidade fisiológica, do temperamento, do gênero, da idade, entre outros como pontos a serem considerados na criação de um mundo pessoal.

Se propondo a evidenciar os diversos condicionantes para essa vinculação do homem com o espaço, o que é uma tarefa muito complexa, Tuan é bem sucedido ao abrir os temas que são os diversos condicionantes para o homem se perceber no espaço. Neste sentido, termina por abrir temas e uma agenda de pesquisas, o que acabou estimulando avanços sobre as pesquisas em geografia cultural.

Nesse clássico, Yi-Fu Tuan, difunde o termo topofilia (descrito por Bachelard) entendido em um sentido amplo, como os laços afetivos (simbólicos) dos seres humanos com o meio ambiente. "Topofilia" descreve uma sensação que pode não ser a mais forte das emoções humanas, de fato, muitas pessoas se sentem totalmente indiferente em relação aos ambientes que moldam suas vidas, mas quando ativado ele tem o poder de elevar um lugar para tornar-se o portador de eventos emocionalmente carregados ou para ser percebido como um símbolo. O termo, como dito, vincula-se à afetividade, os laços estabelecidos com o ambiente considerando muito da subjetivação humana, assim, revela o ser geográfico, o Homem, a sociedade como criadora de significado, por uma natureza que interpreta, tornando a ciência geográfica mais humana e subjetiva, ampliando seu entendimento para além de uma ciência dos lugares.

"Topofilia" se associa ao sentido geográfico de lugar, escala da ação e experiência e passa a fazer parte dos estudos de percepção ambiental. "Topofilia" como relação amorosa com a terra, abre uma série de estudos que levavam em consideração a observação da paisagem, manifestações afetivas, elementos da cognição, percepção e mesmo comportamento do homem diante de seu meio. Nesse sentido, este neologismo exprime a filiação do ser humano para com o ambiente que o cerca, da associação da pessoa ao lugar de vida.

Para subsidiar esse novo conceito, Tuan estabeleceu uma exploração ampla de como os laços emotivos com o ambiente material variam muito de pessoa para pessoa e em intensidade, sutileza e modo de expressão. Fatores que influenciam a sua profundidade de resposta ao ambiente incluem fundo cultural, de gênero, raça e circunstância histórica, argumentando também a existência da capacidade sensorial, inata, o elemento biológico e sensorial.

Embora inspirado em aclarar sua proposta de entendimento sobre o lugar, algumas vezes traz interpretações curtas, puramente antropológicas ou puramente estéticas para significação dos lugares, a vontade é de mergulhar em uma determinada cultura, de um lugar e absorver a complexidade dos múltiplos condicionantes.

Explicitando as forma como os sentidos (visão, olfato, audição, tato) atuam nas maneiras do homem responder, reconhecer e atuar no mundo, com os estímulos ambientais nos tocando, de maneira diferente de outros animas, ressalta que o Homem aprecia a sensação de compressão do espaço, pelo acúmulo de informações simultâneas táteis, auditivas, visuais, olfativas que permitem que os humanos sintam as distâncias, às direções dos eventos, todos esses sentidos fazem parte do processo de reconhecimento espacial.

"O mundo percebido pelos olhos é mais abstrato que o conhecido por nós por meio de outros sentidos" (TUAN, 2012, p. 28). Apesar de abstrata, o autor considera a visão a faculdade mais valiosa do homem, sendo a capacidade de dar significado ao acúmulo de sensações o que nos diferencia dos animais. Os humanos possuem comportamento simbólico e constroem mundos mentais para se relacionarem entre 
si e com a realidade exterior. Ao discorrer sobre a fisiologia que nos permite estabelecer nexos, também ressalta diferenças na escala de percepção de alguns grupos culturais e também da segmentação, ou sistematização temporal para marcar a compreensão do tempo.

Pormeio de caracterizações de alguns povos, mostraque percepções, sensações mais apuradas dependem das necessidades do ambiente, como a dos Aivilik, esquimós que diferem diversos termos para ventos e também para gelo, pois estes são uma referência importante para sua localização em um ambiente onde a cor do céu e da terra se confundem e não há referenciais na paisagem. Há necessidade de adequação, e conhecimento do meio faz com que as pessoas desenvolvam formas de perceber o meio, de maneira que lhe seja útil, fazendo com que haja formas culturais de sentir com um ou outro sentido mais aguçado, por particularidades do meio físico em que se habita.

Trazendo também a evolução na forma como o Homem se compreende no ambiente, de um período medieval às cidades modernas e planejadas, faz uma comparação com visões do campesino e do citadino, mostrando que há formas, influências que são universais, mas há muitas diferenças na forma de sentir seu espaço, com suas idiossincrasias, com cada grupo e cada indivíduo construindo uma nova ideia da relação com um ambiente. Por uma série de exemplos fica claro que o Homem tem a tendência de diferenciar seu espaço etnocentricamente.

O autor apresenta diferentes cosmologias, principalmente orientais, e sua respectiva significação de pontos cardeais, por substâncias, elementos da natureza (terra, fogo, ar, água), cores, sentimentos, comportamento muito por base na filosofia oriental, do I ching e esse costume de estruturar o mundo estimula uma visão simbólica. Examinando os valores e formas de percepção ambiental, para diferentes grupos, trazendo riquíssimas informações sobre diversas culturas, indígenas, modernas, chinesas, indonésias descrevendo as experiências, formas de ocupar e se entender no espaço. Essa diversidade faz da obra realmente rica, fluída, porém se apresentam como pequenas fotografias de diferentes práticas em relação ao meio, pontos em suspenso, sem mergulhar em determinada particularidade.

Cada grupo estabelece costumes, em contraponto às forças culturais homogeneizadoras. Essa necessidade de manter práticas particularidades a cada grupo cria a ilusão de superioridade e centralidade e, segundo Tuan, essa diferenciação com qualificação superior é o que faz com que a cultura se mantenha (TUAN, 2012, p. 55.). A criação desses ideais e formas prontas de significação pode ser uma necessidade para a manutenção da cultura. Para ilustrar essas particularidades, Tuan apresenta a descrição de diagramas cósmicos de alguns povos, indicando a percepção espacial evidenciada nos mapas e a compreensão de sua posição espacial no mundo.

O autor trabalha com a escala de indivíduos e de grupos culturais. Com base na pedagogia e na psicologia, descreve os contrastes das formas de comportamento e visões do mundo variando de acordo a subjetividade em cada um. Revela os mundos pessoais, com suas preferências, individualidades fisiológicas (subjetividade e variações na percepção de cores e temperatura), temperamento, talento, atitude, gênero, idade (a surpresa e imaturidade de um infante, o desgaste dos sentidos, ferramentas para percepção nos mais idosos). Ao ressaltar a carga histórica das experiências vividas, da cultura construída para definir as atitudes do homem com o ambiente traz a discussão de cultura como definidora de padrões, de formas de enxergar e sentir o ambiente, com definições de verdades que são bastante arbitrárias, advindas de convenções e práticas culturais. 
Ao abordar o meio ambiente, percepção e visões de mundo, o autor enfatiza como o mundo material, atua na percepção e nas atitudes dos Homens, moldando forma de ver o mundo. "O prazer visual da natureza varia em tipo e intensidade, podendo ser um pouco mais do que a aceitação de uma convenção social" (TUAN, 2012, p. 139). Por exemplo, as perspectivas no campo de visão, em meios mais fechados como florestas tropicais onde tudo é visto à curta distância se opõe a meios abertos como grandes desertos. Os bosquímanos que, ao sair pela primeira vez da floresta com um novo horizonte à frente, imaginam que os búfalos observados à distância são pequenos insetos pois, não conhecem a noção de perspectiva nessa escala ampliada.

De maneira muito rica, Tuan descreve as particularidades, costumes e portanto visões de mundo, dos povos mesopotâmios, egípcios, acentuando os símbolos, arquiteturas que os caracterizam. Pontua também diferenças no Homem urbano e rural construídas por elementos do ambiente social e físico pois, em ambientes dicotomizados há atitudes dualistas, pela estruturação da vida em pólos (mal e bem, escuro e claro).

Expõe também os meios pelos quais os seres humanos respondem ao ambiente, porsua apreciação estética, efêmera, repentina ou percebida pelos sentidos, tátil, visual, auditiva, a história e reconhecimento, vinculado ao sentimento de pertencimento pelos vínculos históricos das famílias, "A consciência do passado é um elemento importante no amor pelo lugar" (TUAN, 2012. p. 144).

Ao falar do impacto da urbanização na apreciação do selvagem em um período pretérito, em que apenas após o aparecimento das grandes cidades [na época da Alexandria] aparece uma forte reação contra a sofisticação urbana e o anseio pela rusticidade (TUAN, 2012, p. 153). Hoje, no mundo urbano ressalta-se o contato físico com o próprio ambiente natural é cada vez mais indireto e limitado a ocasiões especiais, como o ecoturismo moderno. Esse signo de viagens ao ambiente, de sensação a ser experienciada para significação e compreensão do homem no mundo Também têm embutida uma noção de criação de identificação e pertencimento à aldeia global e sobre isso Tuan ressalta a mania de fotografia em ponto turístico, como comprovação de existência do mundo, e de ideais compartilhados em uma comunidade.

Ainda sobre a urbanização, Tuan olhando a realidade norteamericana na década de 1970, descreve uma prática muito comum nos dias atuais, em grandes metrópoles adensadas, onde a pureza do ar e da água está se tornando rara, já não existe grande quantidade desses elementos livres na natureza. A valorização natureza, atualmente tem grande salto, dada sua escassez dessa paisagem, nesse momento, "quando uma sociedade alcança certo nível de desenvolvimento e complexidade, as pessoas começam a observar e apreciar a relativa simplicidade da natureza" (TUAN, 2012, p. 148). Essa valorização advém da crise do visual opressor da selva de pedras que se associa a divulgação de ideais ambientalistas e as funções ecológicas, sociais e econômicas, com o reconhecimento psicológico, ecológicos dos benefícios que trazem o contato com o meio físico menos alterado.

A natureza selvagem deixa representar ambientes hostis ao ser humano para transformar-se em ambientes que proporcionam beleza e prazer à visão, com fins de apreciação estética, portanto, "o envolvimento do homem tecnológico com a natureza é mais recreacional que vocacional" (TUAN, 2012, p. 139).

Muitos dos conceitos de Tuan referem-se à emoção com que o homem se relaciona com uma escala do espaço que faz dele um lugar humano, individualizado por sentidos positivos de pertencimento, proteção, segurança ou um território como uma área com fronteiras, marcada pelo sentimento de posse, de preservação e defesa do ponto de vista das comunidades. 